\title{
HYDRAULIC ANALYSIS OF CAUSES OF WASHOUT OF GDYNIA-ORŁOWO SEA-SHORE DURING THE FLOOD IN THE KACZA RIVER ESTUARY
}

Michał Szydłowski

Gdańsk University of Technology, Faculty of Civil and Environmental Engineering, Poland

\begin{abstract}
In July 2016 in the Three-city agglomeration a rainfall episode of over a day duration and $150 \mathrm{~mm}$ summary rainfall height, occurred. This situation, extreme as for Polish conditions, caused significant freshets in rivers and streams running into Gdansk Bay, the Baltic Sea, and serving as collectors of rainfall waters for the sea-coast towns. In many areas of the Three-city flood phenomena and overflows took place. The flood also occurred in the catchment area of the Kacza river in Gdynia. The passing of flood water rise caused damage of many infrastructure objects located along the river valley. The estuary section of the river suffered most, especially sea-shore belt together with beach around the estuary which were significantly washed out. In this paper an approach was made to answer to the question on direct causes of the situation which occurred at the estuary of the Kacza river. To this end, there was worked out a hydrodynamic model of the considered section of the river, based on the solving of two-dimensional differential motion equations of free-surface liquid, and simulations of water flow propagation along the river's valley were performed for a few variants of hydraulic engineering infrastructure of river bed. Numerical hydraulic analysis made it possible to determine a role of the hydraulic engineering objects in forming the flood water rise as well as their impact on location and range of washout zones of sea-shore belt.
\end{abstract}

Keywords: hydrodynamics,flood,erosion of the coastal zone,Kacza river,Gdynia

\section{INTRODUCTION}

The Three-city agglomeration is located on the terrain adjacent to Gdansk Bay of the Baltic Sea, which is very differentiated as to its height over sea level. The terrain height changes from the Gdańskie Żuławy depression up to almost $200 \mathrm{~m}$ in the area of moraine hills a few kilometres distant from the Baltic Sea coastline. The so specifically shaped terrain of the Three-city affects spatial distribution and temporal run-off process of atmospheric precipitation, often causing the rise of local rainfall height due to an orographic mechanism $[7,8,3]$. Simultaneously, with the building development work carried out on the moraine hills, surface and bed rainfall run-off along the streams and rivers reaching Gdansk Bay has been increased. Beds of these watercourses serve to day as collectors in the rainfall catchment system. However their capacity is limited hence during violent rainfall run-off their overload resulting in flooding urban areas often occurs. In this century we have had to do with urban area flooding both in Gdańsk in 2001, 2010 and 2016 [2] as well as in Sopot and Gdynia in 2016 [9]. Additionally, a tendency to occurrence of heavy rainfalls of summary heights exceeding $100 \mathrm{~mm}$ [5] is a cause of elevated risk to urban area flooding in Three-city. This paper presents a hydraulic analysis of causes of a seashore washout at the Kacza river estuary in Gdynia-Orłowo during the flood of 2016. In July 2016 in the Three-city agglomeration a rainfall episode of over a day duration and $150 \mathrm{~mm}$ summary rainfall height occurred. It is impossible to determine precisely how the rainfall was distributed over 


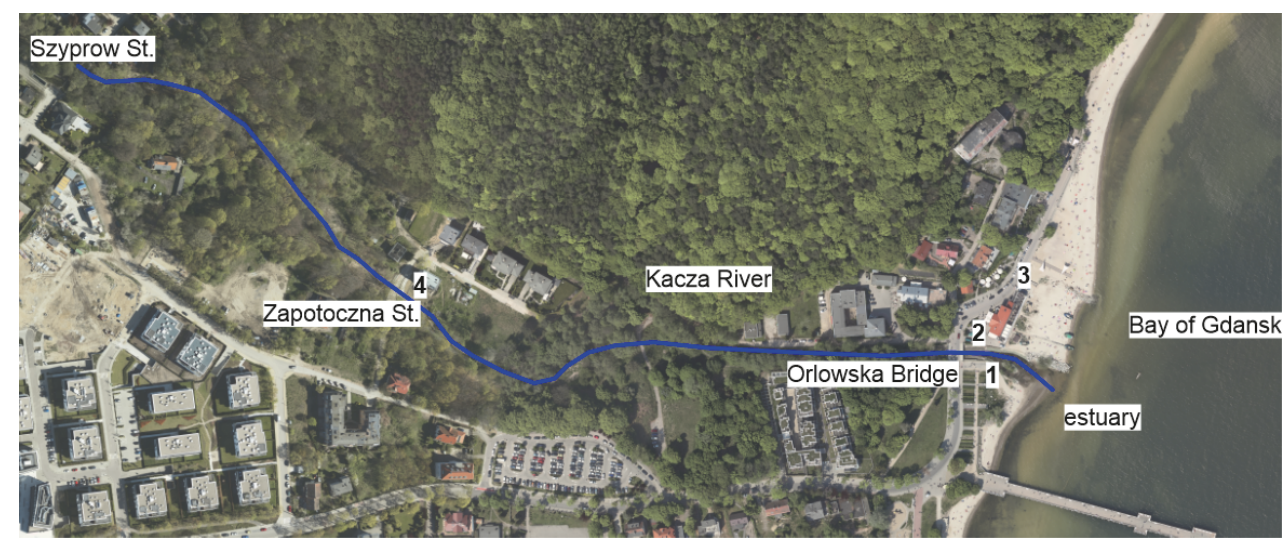

Fig. 1. The Kacza river estuary section with enumeration of flood-damaged places shown in Fig. 2. (image prepared by these authors on the basis of an ortophotomap from geodesic resources of Gdynia city, Gdynia Municipal Council licence No. PND.6642.1.1697.2018_2262_N, without scale)

Gdynia area and how big values of water flow rate in the river were as there is no control over the Kacza river catchment basin. However, it is probable that summary rainfall height could be similar to that measured in the same time at the station Gdańsk Oliwa (170,2 mm) and Gdańsk Osowa (161,9 $\mathrm{mm}$ ) [5]. The so high daily rainfall amount was a direct cause that the Kacza river overflowed its banks in many sections of its full length. The freshet wave propagation resulted in the damaging of many infrastructure objects located along the river's valley. The estuary section of the river suffered most, especially the sea- shore belt together with the beach close to the Orłowo pedestrian pier at the river's estuary (Fig. 1), which appeared to be washed out along a significant length.

On the analyzed estuary section of the river (covering 800 $\mathrm{m}$ length from the Gdansk Bay coast) the greatest damages and losses were associated with heavy washout of banks and bed of the river and its valley beneath Szyprów street, water damming up and breaking the road embankment along Zapotoczna street, flooding the areas adjacent to the river -bed before the Orłowska street bridge as well as washout of the sea-shore belt together with the beach and touristic infrastructure below the bridge in Orłowska street. The photographs showing example damages resulting from the freshet run-off along the Kacza river estuary section are presented in Fig. 2.
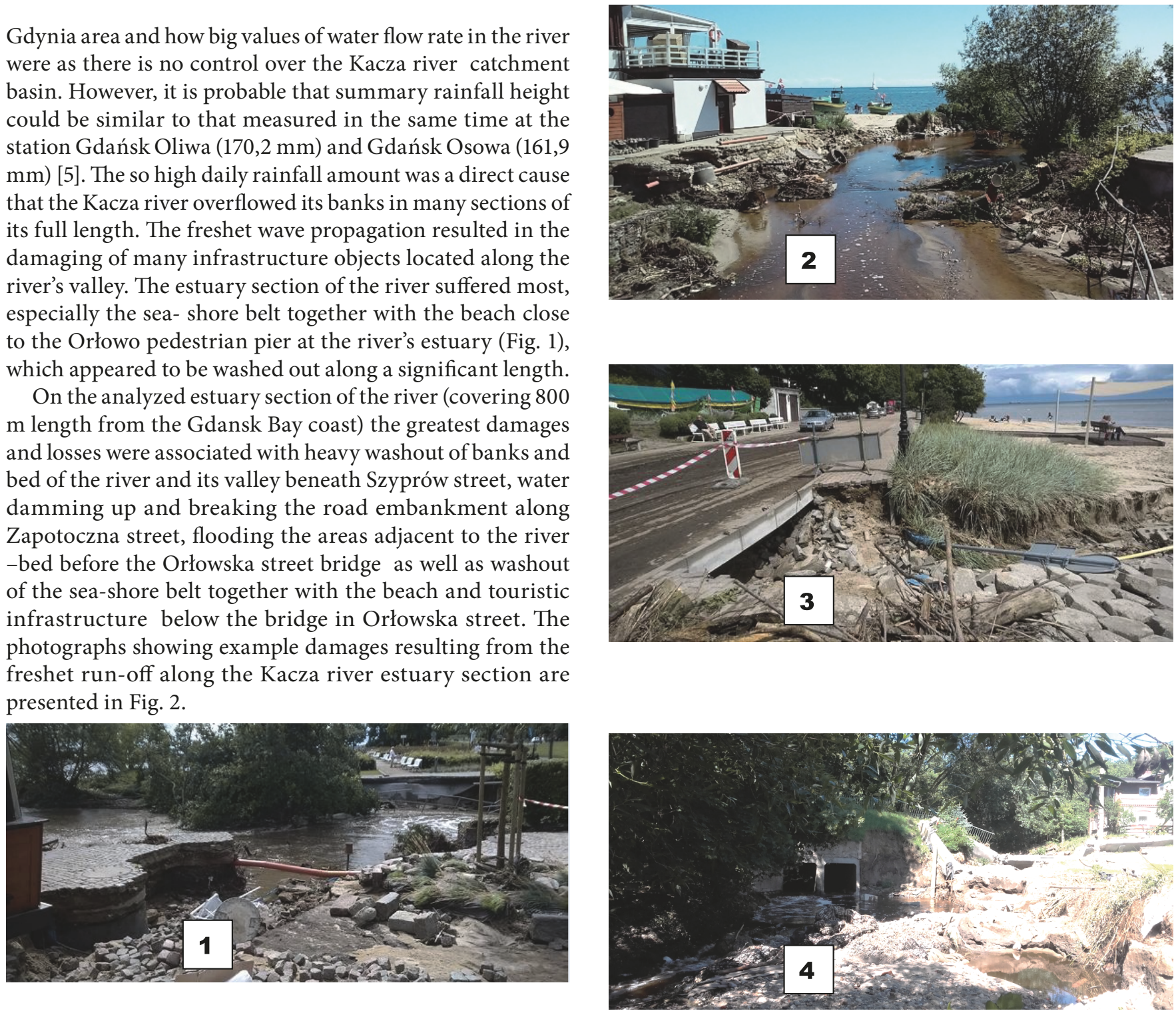

Fig. 2. Damages in the Kacza river estuary area in Gdynia Ortowo as a result of the freshet in July 2016 (photos No. 1, 2, 3-washout of sea-shore belt below Orłowska street bridge, photo No. 4 - breach in road embankment of Zapotoczna street. Location of subsequent shots - see Fig. 1. (acc. this author's archive) 
In the context of the so vast damages of the river estuary and sea-shore belt an interesting question arouse as to a direct cause of the situation. Worth stressing that the flooding incidents do not depend only on freshet flow rate resulting from an increased run-off of rainfall water from the river catchment basin. On flooding danger also decide water states in particular flooded areas, and these depend not only on water flow rate but very much depend on current flow passage capacities of water-courses and their hydraulic engineering infrastructure such as bridges and culverts. The double culvert located in line of Zapotoczna street may serve as an example of such object in the Kacza river estuary section in Gdynia. During the flood of July 2016, as a result of blocking the culvert outlet by floating trees, branches and bed load, the river valley above the embankment of the Zapotoczna street filled in with water and after exceeding the top of the embankment ( abt. $4 \mathrm{~m}$ above the river bed ) suffered a washout resulting in an uncontrolled water run-off to the river bed. In this work an attempt was made to show which role for damage of the sea-shore belt and beach in Orłowo has been played by the increased ( natural) rainfall run-off from the river catchment basin as well as by hydraulic engineering objects. To this end, it was necessary to work out a numerical model of the river and perform various simulations of freshet wave flow in the Kacza river bed along its estuary section. Simultaneously it should be stressed that in this work attention was paid only to potential causes of the sea-shore belt washout, but the washout phenomenon itself was not analyzed.

\section{METHODS AND DATA}

To correctly represent the complex structure of water flow over the flooded area it is necessary to carry out simulations by making use of a two-dimensional motion model of liquid. Moreover, while in the situation of stationary flow to use simplified models is sufficient, e. g. in the form of Helmholtz bi-harmonic equation [10], in the case of flood water flows varying with time the application of transient motion equations is necessary.

In the presented paper the simulations of water flow along the Kacza river bed were made with the use of a hydrodynamic model of two-dimensional flow of free-surface water. The model equations were solved by using the HEC-RAS calculation system [1], under transient flow conditions. The two-dimensional model of horizontal free-surface water flow applied in this system is a set of shallow -water flow equations [6]. The main assumption used for building the model is a slow variability of water motion. There is also assumed that vertical velocity component is negligible that results in a lack of vertical accelerations, pressure distribution is hydrostatic, and bed slope values are small. In the two-dimensional case, after neglecting momentum dissipation due to turbulence, as well as momentum dispersion resulting from velocity averaging, the form of the transient flow equations is as follows:

$$
\begin{gathered}
\frac{\partial h}{\partial t}+\frac{\partial(u h)}{\partial x}+\frac{\partial(v h)}{\partial y}=0 \\
\frac{\partial(u h)}{\partial t}+\frac{\partial\left(u^{2} h\right)}{\partial x}+g h \frac{\partial h}{\partial x}+\frac{\partial(u v h)}{\partial y}-g h\left(S_{o x}-S_{f x}\right)=0 \\
\frac{\partial(v h)}{\partial t}+\frac{\partial(v h)}{\partial y}+g h \frac{\partial h}{\partial y}+\frac{\partial(u v h)}{\partial x}-g h\left(S_{o y}-S_{f y}\right)=0
\end{gathered}
$$

The symbols $\mathrm{x}$ and $\mathrm{y}$ represent spatial variables, $t$ - time, $g$ - Earth gravity acceleration, $h$-water depth, $u$ and $v$-flow velocity vector components averaged over the depth, $S_{\mathrm{o}}$ and $S_{\mathrm{f}}$ - terrain and energy linear slopes, respectively. The set of equations $(1,2,3)$ is that of partial differential equations of hyperbolic type whose solution for an assumed initialboundary conditions are the functions $u(x, y, t), v(x, y, t)$ and $h(x, y, t)$. In certain cases where to neglect inertia force in the equations $(2,3)$ is possible, the above mentioned model is simplified to the so called diffusion wave model. However, in the performed analysis such simplification was not implemented in view of a significant role of inertia forces in dynamics of freshet flow through the relatively narrow valley of the river in question and fast-varying motion conditions. In the calculation system HEC-RAS the flow equations $(1,2,3)$ are solved by using the finite differences method [1]. Numerical solution of the equations requires to assume a space of solutions of the equations as well as boundary conditions. The solution space is composed by geometry of a surface over which water flow occurs and duration time of flow phenomenon. The geometry can be defined by assuming physical boundaries of flow, whereas the time is usually chosen on the basis of a necessary duration of simulation process. Moreover, to solve the flow equations it is necessary to define configuration of the terrain over which water flows as well as its coverage which affects hydraulic drag occurring during the motion.

The information about configuration of the terrain in the area of the Kacza river valley was taken from the numerical model prepared for the city of Gdynia ( Gdynia Municipal Council licence No. PND.6642.1.1697.2018_2262_N). The model is characteristic of $5 \mathrm{~m} \mathrm{x} 5 \mathrm{~m}$ horizontal mesh resolution and the average height error not greater than $0,8 \mathrm{~m}$. Fig. 3 shows a visualization of the terrain of Kacza river valley elevation system in the analyzed section of its estuary. The terrain ordinates change upstream the river from $0 \mathrm{~m}$ on sea level at Gdansk Bay coast up to almost $16 \mathrm{~m}$ on the level of Szyprów street distant a little more than $800 \mathrm{~m}$ from the estuary. In this area the highest hills of the moraine range neighbouring the river reach $70 \mathrm{~m}$ above sea level. The boundary of the calculation area and its numerical mesh was so assumed as to obtain the possible highest values of water table ordinates but not exceeding river banks along the valley and to make the water flow possible only through the affluent cross-section (upper) at Szyprów street and confluent one ( lower) located at Gdansk Bay coast. The numerical mesh was assumed of the density close to the terrain model resolution, by dividing the flow area into $5 \mathrm{~m} \times 5 \mathrm{~m}$ squares. 


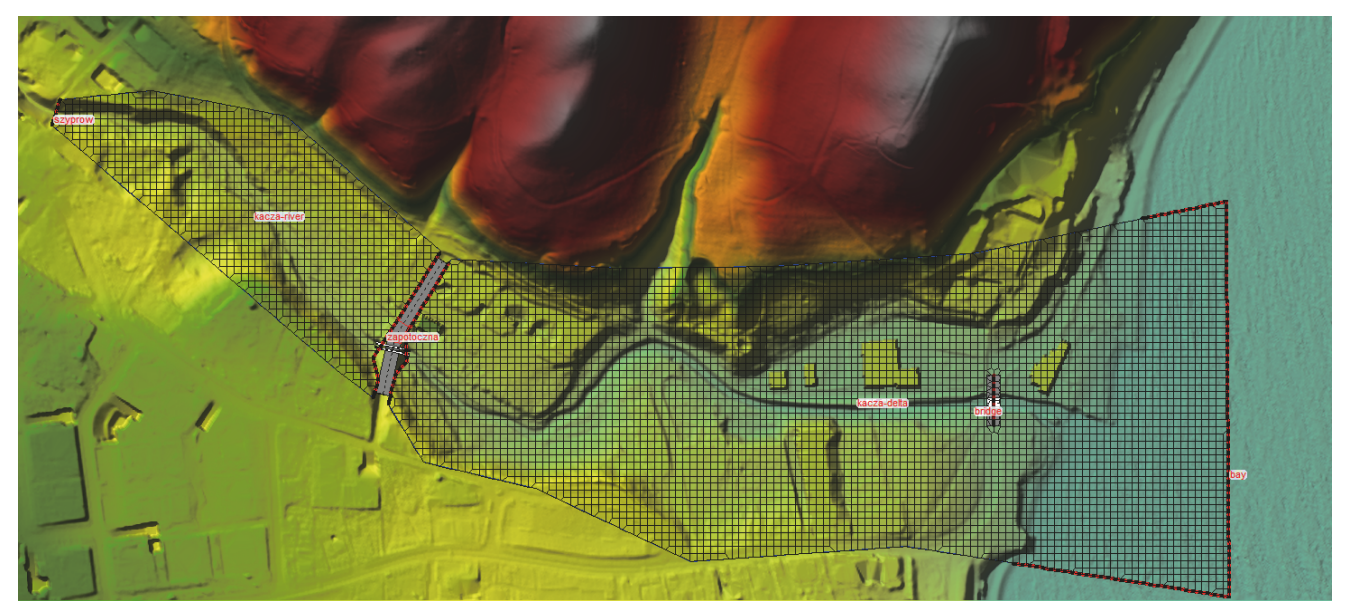

Fig. 3. The numerical model of the considered terrain around Kacza river (GMC licence No. PND.6642.1.1697.2018_2262_N) as well as the calculation area boundaries together with hydraulic engineering objects and sites where boundary conditions were set.

The limit conditions necessary to solve the hydrodynamic model equations are composed of initial conditions and boundary conditions. The first of them define values of searched functions (of filling and flow velocity) at the initial instant, i.e. before initiation of simulation of water flow phenomenon. In the carried out analyses there was assumed that the initial situation will correspond to usual ( without freshet) flow conditions in Kacza river. The average multi-year flow rate in the river estuary is equal to about $0,3 \mathrm{~m}^{3} / \mathrm{s}$, that is two orders lower than flood flow rates which can reach even more than $20 \mathrm{~m}^{3} / \mathrm{s}$ [9]. The so large discrepancy allows to neglect the initial (basic) flow rate in the river and to assume an initial condition in the form of a lack of water in the entire valley. The second of the limit conditions ( boundary conditions) define all inflows and outflows through boundaries of the flow area. For the simulations two open sections of the river bank with set boundary conditions were selected. In the affluent crosssection (Szyprów street) there was assumed a water flow rate in the form of a hypothetical hydrograph of $20 \mathrm{~m}^{3} / \mathrm{s}$ culmination corresponding to the flood situation in the estuary section of the river. For simulation of the flood the following temporal variability of flow rate was assumed: $\left(\mathrm{T}[\mathrm{h}], \mathrm{Q}\left[\mathrm{m}^{3} / \mathrm{s}\right]\right):(0,0)$, $(3,5),(6,20),(9,20),(12,5)$. At the confluent cross-section( Gdansk Bay) free - water outflow into the sea was assumed. The remaining boundaries were assumed to form a close embankment simultaneously ensuring prevention against water coming to the considered areas.

In the numerical model of the river there was represented also the hydraulic engineering infrastructure located in the river bed, which determines freshet flow course through the considered river fragment. Beneath Szyprów street two important engineering objects are situated - the culvert in the road embankment of Zapotoczna street and the bridge in the line of Orłowska street. The culvert in question is fitted with two square channels of $1,5 \mathrm{~m}$ x 1,5 m each whose bottom from the outlet side is placed on the ordinate of $6,10 \mathrm{~m}$ above sea level. Simultaneously the road embankment crossing the entire river valley has the lowest ordinate of its crown located $10,0 \mathrm{~m}$ above sea level. Such situation results in that when the freshet wave exceeds the culvert channels passage capacity the water damming- up occurs in the valley upstream the embankment and the whole system works as a retention reservoir. However in view of that the road embankment was not designed and built as a water dam its structure and a lack of any emergency surface water draining system result in that, after filling up, water flow over the embankment top and washout of its body occur. Such situation happened during the flood of July 2016 after a partial blockage of the culvert inlet by floating wood material waste, which resulted in forming a breach in the embankment (Fig. 2, Photo 4) and in consequence leading to a collapse of the object. It resulted in an instantaneous significant rise of the flow rate in the valley below Zapotoczna street. In the numerical model of the engineering object it was made also possible to reconstruct the breach forming process.

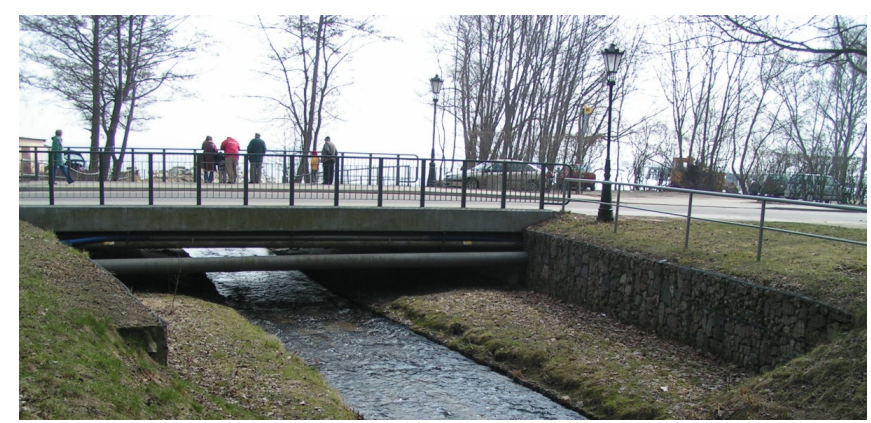

Fig.. 4. The bridge over Kacza river in line of Orłowska street in Gdynia ( a photo from this author's archive),

The second object (the bridge in line of Orłowska street) is built in the form of a reinforced concrete plate supported only on its heads ( lack of abutments). Its breadth amounts to $11,0 \mathrm{~m}$ and the height to $1,5 \mathrm{~m}$. The upper ordinate of the plate is close to that of the surrounding terrain. Below the bridge there are located pipelines which obstruct a significant part of the free cross-section area under the bridge from the side of inlet. (Fig. 4). 


\section{NUMERICAL SIMULATIONS AND DISCUSSION OF RESULTS}

In the frame of the hydraulic analysis of transformation of freshet wave through Kacza river valley in its estuary section, the calculations of water flow conditions were carried out in three variants. In all three cases the same conditions of river inflow to the cross-section in the vicinity of Szyprów street, with $20 \mathrm{~m}^{3} / \mathrm{s}$ culmination of freshet flow rate were assumed. The reconstructed phenomenon duration time was taken equal to $10 \mathrm{~h}$ for all the cases. In variant 1 the flow through full cross-section area of the culvert channels in the Zapotoczna street embankment as well as a lack of breach in the embankment, was assumed. Such situation results in that the maximum flow rate in the valley below this place does not exceed the river inflow culmination rate of $20 \mathrm{~m}^{3} / \mathrm{s}$. In variant 2 a scenario close to the episode of the flood in July 2016 was assumed; it consisted in the decreasing of the flow passage capacity of the Zapotoczna street culvert's channels by blocking by $50 \%$ of their inlet cross-section area, that corresponds to the eye-witness accounts. There was also assumed that when water level exceeds the top of the embankment a washout of its body occurs and within an hour a breach of $15 \mathrm{~m}$ breadth in bottom and 8,0 m bottom ordinate over sea level is formed, that reproduces the historical event effects. To precisely reconstruct the
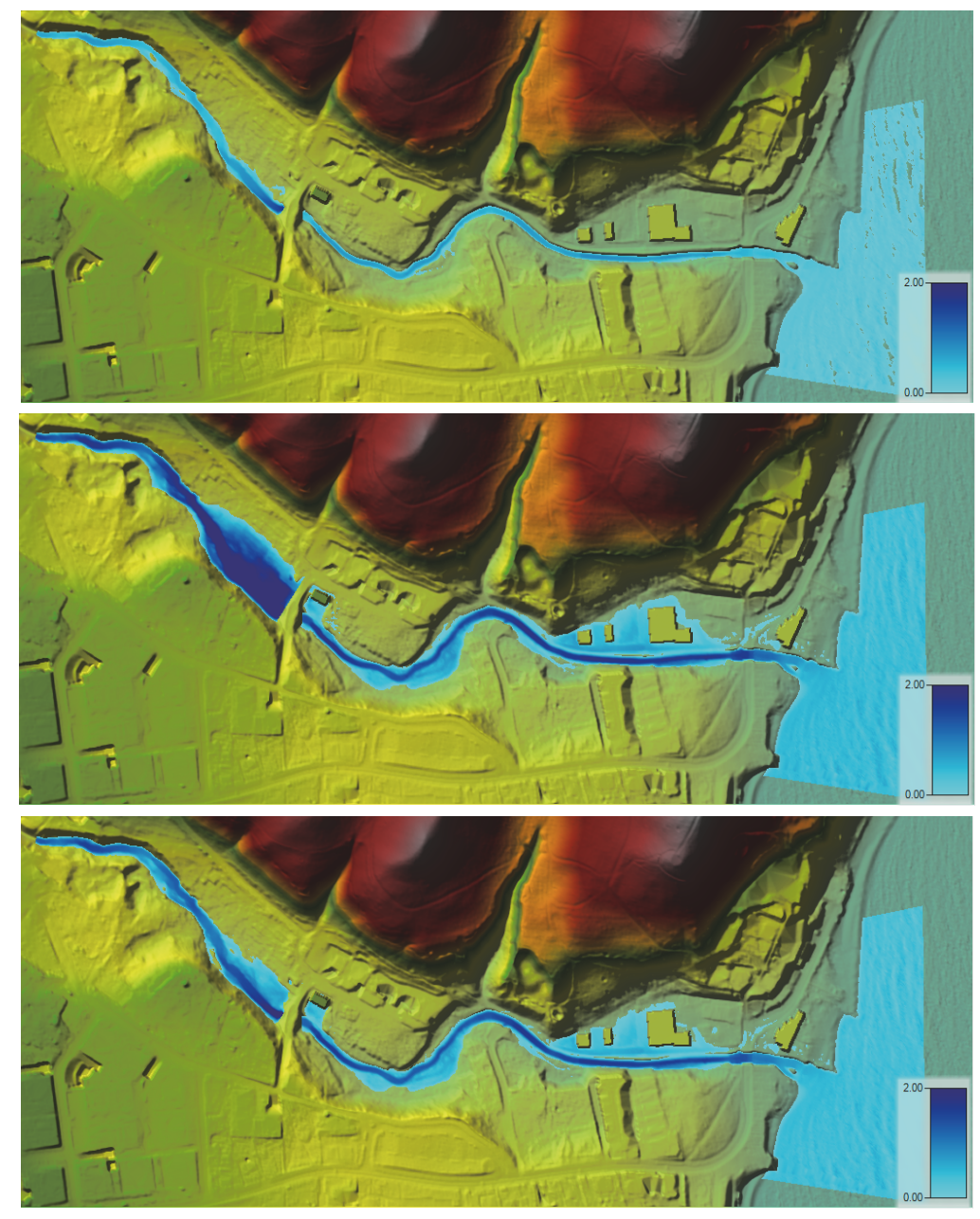

accident was not possible due to a lack of measurements. A consequence of the so assumed scenario was the increasing of the maximum flow rate below the object over the value of the inflow culmination rate, resulting from a violent release of the water gathered ( retained ) in the valley ( reservoir) above the road embankment. Variant 3 is identical to variant 2 as to the flow conditions through the culvert in the Zapotoczna street embankment, but the mode of hydraulic behaviour of the bridge in Orłowska street was modified. In the last variant the assumed cross-section height under the bridge was decreased by $30 \%$, that was intended to reproduce the reduction of the cross-section directly under the bridge due to the presence of the already mentioned pipelines crossing the river valley as well as the stopping of floating wood waste and garbage in the reduced cross-section.

Fig. 5 presents example results of the transformation of freshet wave running through the estuary section of Kacza river valley (variant 2). As can be noticed, up to the instant of forming the breach in the embankment body of Zapotoczna street (at $7^{\text {th }}$ hour of the simulation process) continuous filling in the valley above the embankment can be observed. After damaging the object a violent water outflow through the breach occurs, that results in gradual emptying the reservoir and in the same time instantaneous increasing the flow rate below the object as well as short- lasting spreading the range of flooding in this area.

During a flood, the valley above the embankment, the area situated directly below this object as well as flooding flats around the Kacza river estuary are usually flooded. Left-bank developed area of the Kacza river delta are also flooded, that was also observed during the historical event. However in the presented example simulation the terrain of the sea-shore belt and beach separated from the flooded area by Orłowska street did not suffer any flooding, which shows that the course of the investigated event was different from real one. This question is discussed in the further part of the paper. To find direct causes of damage of the sea shore and beach one should consider maximum parameters of a freshet wave appearing before the Orłowska street bridge which is placed directly above the river estuary and beach. The list of maximum values of water level ordinate and flow rate in three characteristic cross-sections of the valley, i.e. above and below the Zapotoczna street embankment as well as before the Orłowska street bridge, are presented in Tab. 1.

Fig. 5. Changes in the depth $[\mathrm{m}]$ and range of the flooded area, variant 2 ; after 2, 7 and 10 h runoff duration time in Kacza river, respectively 
Tab. 1. Maximum parameters of freshet wave in Kacza river calculated in the selected cross-sections of the river valley

\begin{tabular}{|c|c|c|c|c|c|}
\hline \multirow{2}{*}{ Variant } & \multicolumn{2}{|c|}{ Above Zapotoczna street } & \multicolumn{2}{c|}{ Below Zapotoczna street } & \multicolumn{2}{c|}{ Above Orłowska street } \\
\cline { 2 - 6 } & $\begin{array}{c}\text { Water level } \\
\text { ordinate Hmax } \\
{[\mathrm{m} \text { above sea }} \\
\text { level }]\end{array}$ & $\begin{array}{c}\text { Flow rate Qmax } \\
{\left[\mathrm{m}^{3} / \mathrm{s}\right]}\end{array}$ & $\begin{array}{c}\text { Water level } \\
\text { ordinate Hmax } \\
{[\mathrm{m} \text { above sea }} \\
\text { level }]\end{array}$ & $\begin{array}{c}\text { Flow rate } \\
\text { Qmax } \\
{\left[\mathrm{m}^{3} / \mathrm{s}\right]}\end{array}$ & $\begin{array}{c}\text { Water } \\
\text { ordinate Hmax } \\
{[\mathrm{m} \text { above sea }} \\
\text { level }]\end{array}$ \\
$\begin{array}{c}\text { Flow rate Qmax } \\
{\left[\mathrm{m}^{3} / \mathrm{s}\right]}\end{array}$ \\
\hline 1 & 9.98 & 20.00 & 7.41 & 20.00 & 2.51 \\
\hline 2 & 10.38 & 20.00 & 7.44 & 27.49 & 2.80 \\
\hline 3 & 10.38 & 20.00 & 7.44 & 27.49 & 3.06 \\
\hline
\end{tabular}

\section{Variant 1}

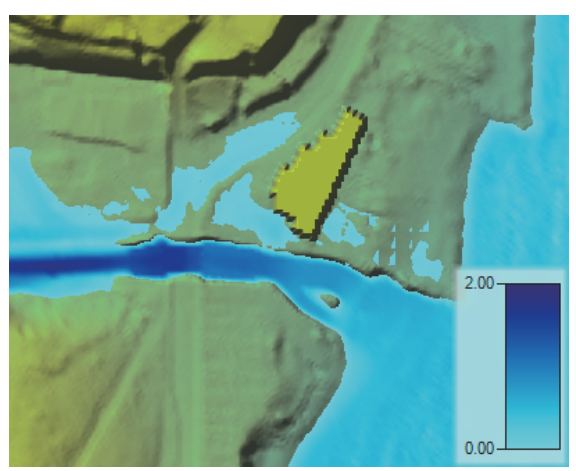

Variant 2

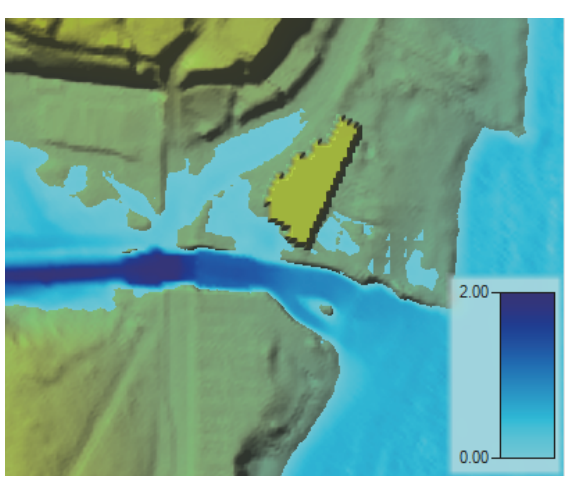

Variant 3
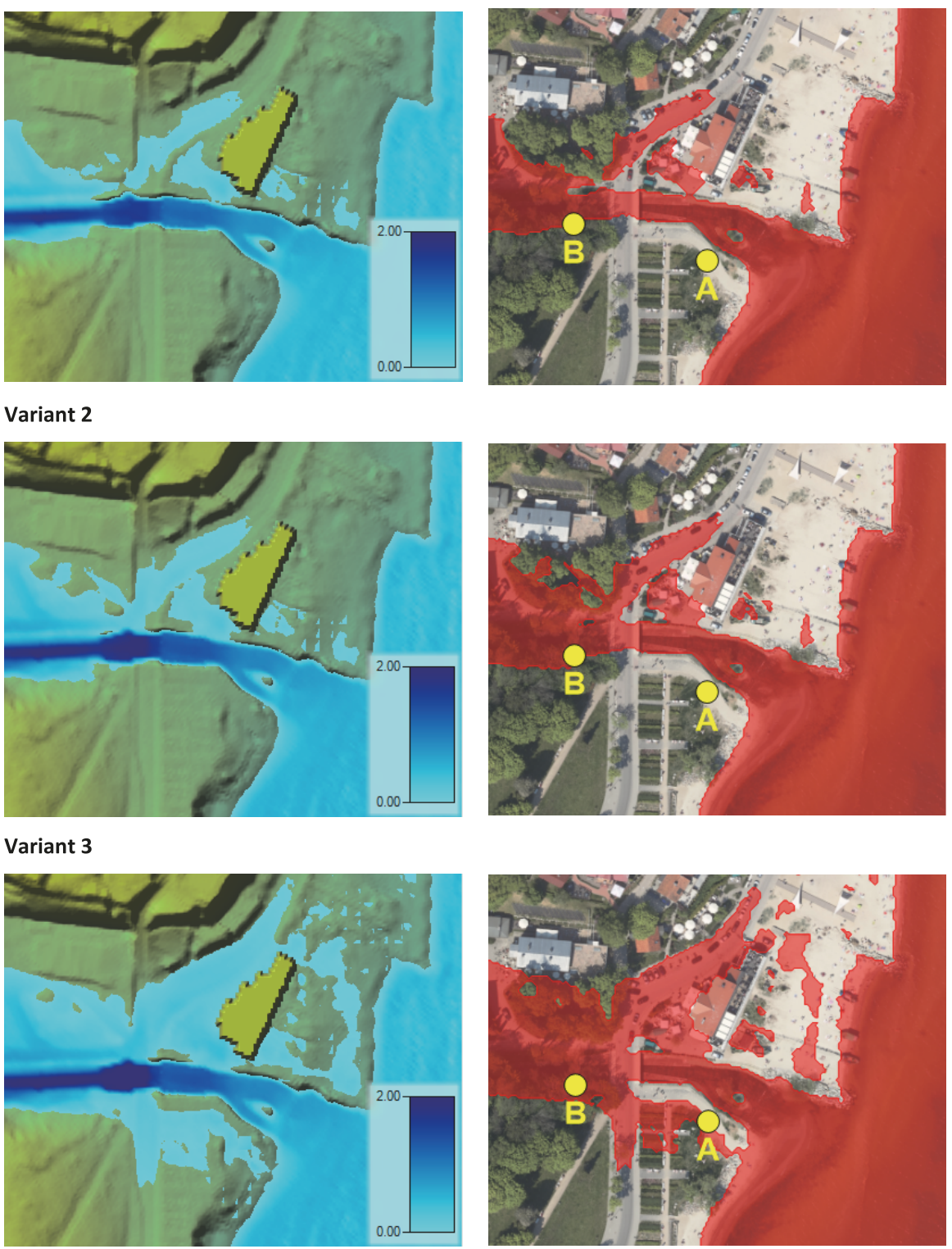

Comparing particular variants one can observed distinct differences in maximum values of the freshet wave hydraulic parameters. First of all values of the culmination flow resulting from the damage in the road embankment of Zapotoczna street (variant 2 and 3) are, below the damaged object, significantly greater (by almost $7.5 \mathrm{~m}^{3} / \mathrm{s}$ ) than the crest of the wave running through the intact object (variant 1). The maximum flows increased as a result of the damage are also observed in the river estuary above Orłowska street. However in variant 3 where the limited flow passage capacity under the bridge is taken into account the reduction of freshet wave culmination is greater due to the greater water damming-up before the bridge and the greater water retention in the flooded areas in the river valley. In the valley cross-section before Orłowska street the damage of the road embankment results, in case of the full water flow cross-section under the bridge (variant 2), in the water damming up to the ordinate of $2.80 \mathrm{~m}$ above sea level, that is greater by almost 0.3 $m$ than that resulting from the simulation without taking into account the object's damage (variant 1), but still not exceeding the bridge plate top ordinate of $2.95 \mathrm{~m}$ above sea level and that of the adjacent terrain. This results in a lack of water flow over the road toward the beach. It means that the freshet wave itself and the forming of the breach could not be the only cause of the observed washout in the river estuary area.

As results from the calculations, a

Fig. 6. Maximum depths $[\mathrm{m}]$ and range of flooded area in the region of Kacza river estuary and Gdynia- Orłowo beach together with depicted measurement points of maximum water level ordinates after the flood in July $2016(A, B)$ (images prepared by this author on the basis of ortophotomap from municipal geodesic resources of Gdynia, Gdynia Municipal Council licence No. PND.6642.1.1697.2018_2262_N, without scale)

factor of a decisive impact on the excessive damming-up of the water and its breaking through Orłowska street was the reduction in the free cross-section area under the bridge resulting from the installation of the pipelines across the river bed (Fig.4). The fact of taking into account the reduction of the free cross-section under the bridge during 


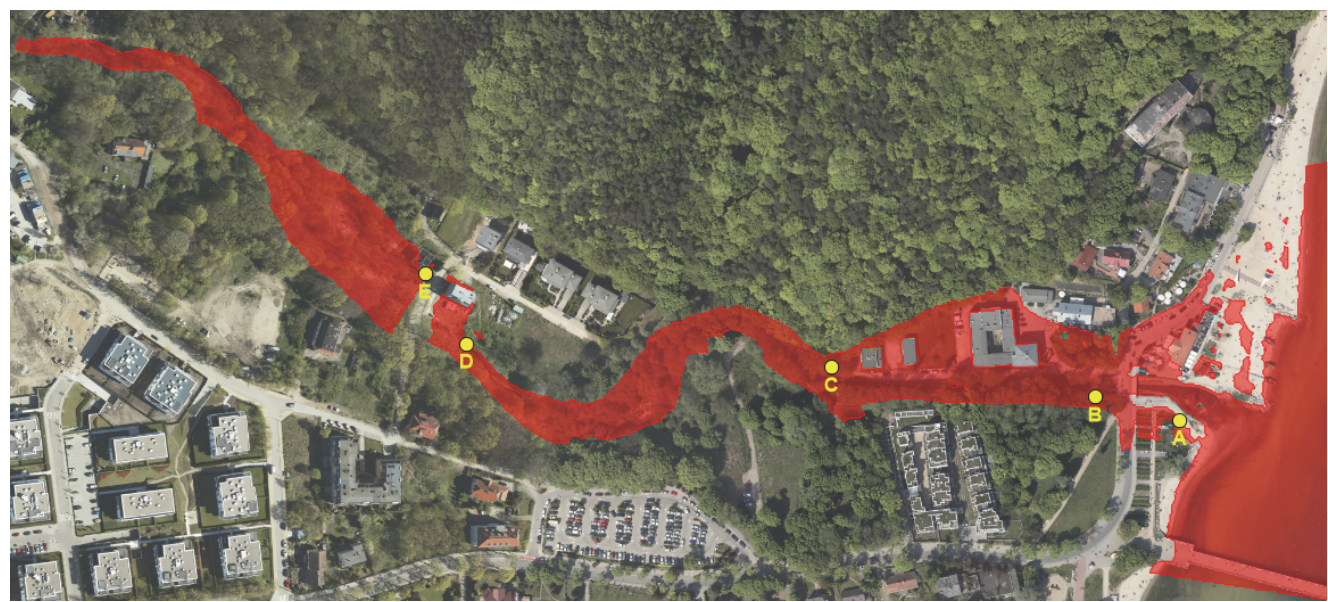

Fig. 7. Maximum range of flooded area along the whole analyzed section of Kacza river in variant 3 together with depicted measurement points ( $A$, $B$, $C$, $D$, E) of maximum water level ordinates after the flood in July 2016 (image prepared by this author on the basis of ortophotomap from municipal geodesic resources of Gdynia, Gdynia Municipal Council licence No. PND.6642.1.1697.2018_2262_N, without scale)

the numerical freshet run-off simulation (variant 3) results in a rise of water level ordinate up to $3.06 \mathrm{~m}$ above sea level and water run-off to the beach over the surface of the Orłowska street.

The differences in the calculated range of flooded area near the Orłowska street bridge and the beach are shown for particular simulation variants in Fig. 6. As can be seen, in successive variants the flooded area range increases and the zones of potential washing -out the sea shore belt and beach spread. Worth mentioning, that the flooded areas indicated in the last graph of Fig. 6 correspond to the location of the washout areas observed after the flood, shown in Fig. 1 (No. 1,2 and 3). Simultaneously, neither in variant 1 nor 2 the flow streams north from the visible building and those on the southern side over the right bank of the river close to its estuary, were reproduced. This way the hypothesis has been proved on the decisive role of the reduced flow passage capacity of the cross-section under the Orłowska street bridge in forming the freshet run-off in the area of Kacza river estuary and its impact on the flood damages resulting in the washout of the sea-shore belt in Gdynia -Orłowo .

In order to quantitatively verify the numerical simulation results as well as simultaneously evaluate the model, a comparison was made between the calculated maximum water level ordinates and the geodesic-measured ordinates of maximum water level in the valley after the flood in July 2016. The measurements were conducted by a team of Gdansk University of Technology during its on-site visit [9]. The points where the measurements were taken are denoted by letters A through E in Fig. 6 and 7. Point A is placed beneath Orłowska street on the right side of the river away its main bed ; point $\mathrm{B}$ is placed above the Orłowska street bridge on the right flooding area of the river ; point $\mathrm{C}$ is situated on the left side of the river directly at its main bed; point D lays directly below the road embankment of Zapotoczna street; point $\mathrm{E}$ is placed above the road embankment. The common list of measurement and calculation results is given in Tab. 2 .
Tab. 2. Geodesic measurements of maximum water level ordinates after the flood in July 2016, and results of respective simulation calculations

\begin{tabular}{|c|c|c|c|c|}
\hline \multirow{2}{*}{$\begin{array}{c}\text { Measurement } \\
\text { point }\end{array}$} & \multicolumn{4}{|c|}{ Water level ordinate [m ] over sea level } \\
\cline { 2 - 5 } & measurement & $\begin{array}{c}\text { simulation } \\
\text { variant 1 }\end{array}$ & $\begin{array}{c}\text { simulation } \\
\text { variant 2 }\end{array}$ & $\begin{array}{c}\text { simulation } \\
\text { variant 3 }\end{array}$ \\
\hline A & 1.75 & brak & brak & 1.72 \\
\hline B & 3.18 & 2.93 & 3.04 & 3.17 \\
\hline C & 3.74 & 3.62 & 3.77 & 3.77 \\
\hline D & 7.45 & 7.15 & 7.41 & 7.41 \\
\hline E & 10.34 & 9.98 & 10.38 & 10.38 \\
\hline
\end{tabular}

Comparing the particular variants, one is able to find differences between the measured and calculated values as well as between the simulation results themselves. Starting the analysis from the upper run of the analyzed section of the river one can observe that in variant 1 where the simulation of blocking the culvert in the Zapotoczna street embankment (point E) is omitted, water run-off over the embankment top (10.0 $\mathrm{m}$ above sea level ) does not occur and no washout of its body happens. Such situation was reproduced in variants 2 and 3 where the calculated maximum water level ordinate is close to that observed. The difference between variant 1 and variant 2 and 3 can be also seen directly below the embankment (point D). In this place where occurrence of the breach in the embankment is not reproduced in the calculations (variant 1) the calculated value of water level ordinate is underestimated by $0.3 \mathrm{~m}$ in comparison to that measured. After taking into account the damage (variant 2 and 3) the difference decreases to $0.04 \mathrm{~m}$ in both the cases, that reflects well on correctness of reproduction of real situation by these simulations. The situation in the middle part of the analyzed section (point $\mathrm{C}$ ) turned out to be similar. Here the simulation result of maximum water level ordinate in variant 1 is also underestimated by $0.12 \mathrm{~m}$ against that measured, whereas the taking into account presence of the breach gives 
the same results in variant 2 and 3, however greater than that measured by $0.03 \mathrm{~m}$. While in the points $\mathrm{E}, \mathrm{D}$ and $\mathrm{C}$ there were observed differences between the results from variant 1 ( without the breach) and those from variants 2 and 3 (with the breach), in points B and A some difference additionally appears between the simulation results from variant 2 (with the breach in the Zapotoczna street embankment and the passable cross-section area under the Orłowska street bridge) and variant 3 ( with the breach and the partly blocked crosssection passage area under the bridge). And, in point $B$ it can be observed that, out of the three simulations, the result from variant 3 is closest to that measured, and in point A ( placed directly near the beach, below the bridge ) the flooding of this area was reproduced only in variant 3 , whereas neither in variant 1 nor in variant 2 the flow over the bridge was properly reproduced. Generally, only the results achieved in the last calculation variant may be considered quantitatively close to the measurements, therefore credible, that has been the aim of validation of the model.

\section{CONCLUSIONS}

The presented analysis was aimed at investigation of a role of natural freshet wave resulting from extreme rainfall episode of July 2016 in Kacza river basin as well as hydraulic engineering infrastructure (culverts, bridge ) located in the river valley estuary section in forming the washout of seashore zone and beach in Gdynia - Orłowo. To reach this aim it was necessary to prepare a numerical model of the river and conduct a few simulation variants of flood run-off. The performed and verified hydrodynamic calculations made it possible to offer the following conclusions summing up the investigations in question :

1. The application of the two-dimensional hydrodynamic model in the form of shallow water flow equations makes it possible to precisely reproduce course of transformation of freshet wave both in natural river beds and valleys and in confluents with engineering infrastructure.

2. The main cause of the flood in July 2016 over the Kacza river estuary section in Gdynia was an increased rainfall run-off from the river catchment basin. As the calculations (variant 1) proved, it could be the cause of flooding the areas above the embankment of Zapotoczna street and the valley ( partially developed ) above the bridge in line of Orłowska street. However it could not cause the water flowing over the top of Zapotoczna street embankment and forming the breach in it (that was really observed ) and also the water flowing over the bridge in line of Orłowska street and the washout of seashore belt and beach because this infrastructure object (culvert) had a sufficient flow passage capacity.

3. The blockage of the culvert inlet by floating broken wood waste, as indicated by eye- witnesses of the damage, should be deemed the direct cause of forming the breach in the Zapotoczna street embankment, that was confirmed by the calculations in variant 2 . Simultaneously, as the numerical simulations proved, the increased water runoff after breaking the Zapotoczna street embankment could not cause the water flowing over the Orłowska street bridge, and thus could not prevent to a large extent against occurrence of the washout of sea-shore belt and beach.

4. The reduction in the cross-section of flow passage area under the bridge due to the engineering infrastructure (pipelines) installed across the river valley above the bridge, proved by the calculations in variant 3 , should be taken as the direct cause of the excessive water damming-up before the Orłowska street bridge and consequently the water overflowing above it towards the beach. Only the cumulated effect of the natural rainfall freshet, the breach in the Zapotoczna street embankment and the reduced cross-section of flow passage area under the bridge caused that the ordinate of Orłowska street was exceeded which in consequence triggered the water flowing down the reinforcements of sea shore and beach toward the sea, which resulted in their damage.

5. The performed simulation calculations in variant 3 were verified by comparing their results with geodesic measurements. The good conformity of calculation results of maximum water table ordinates with the observations proves that the carried out calculations and the way in which scenario of events was assumed, were correct. The achieved calculation results in the form of localization of flooded areas of sea-shore belt are in compliance with the places where damages on the beach and reinforcements were observed during on-spot inspections after the flood; all that makes it possible to

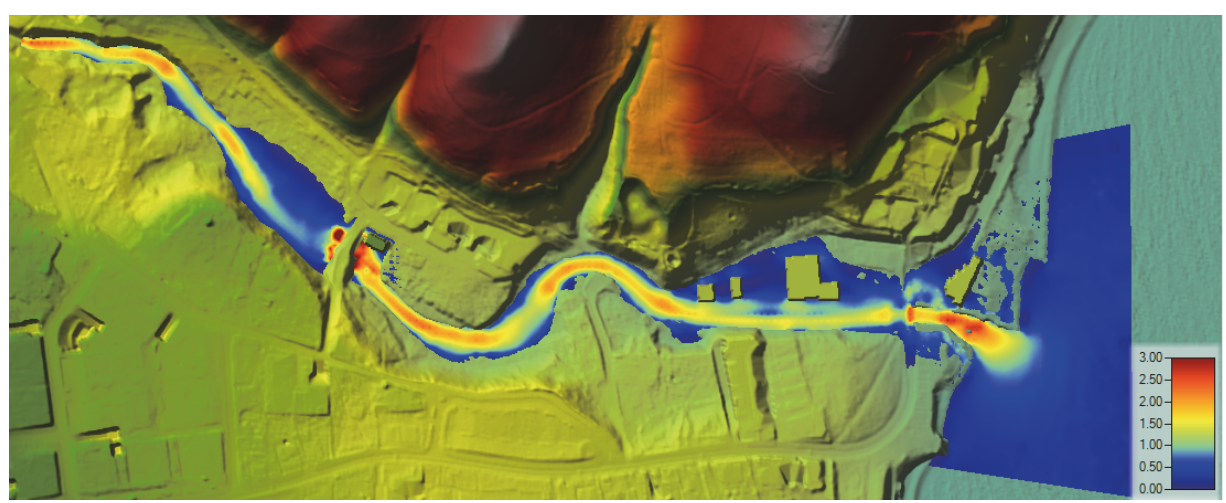

Fig. 8. Maximum calculated flow velocities [ $\mathrm{m} / \mathrm{s}]$ along the estuary section of Kacza river after the flood in July 2016, variant 3 
consider the presented numerical analysis credible.

In conclusion it should be clearly stressed that the fact itself of occurrence of the flooding of the analyzed terrain does not allow to arbitrarily conclude that the washout did happen. The presented maps of flooded areas and/or water depth distributions may only indicate areas prone to washout with predominance of erosion. To confirm occurrence of a washout it is necessary to determine conditions for triggering off soil grains motion, e.g. a limit depth, limit velocity or limit shear stresses [4]. However this question has not been a subject of investigations in the presented work though the results of the worked out modelling could be used to this end by comparing the calculated velocity distributions ( Fig. 8) with the above mentioned limit velocities, i. e. such whose exceeding commences motion of eroded material.

\section{BIBLIOGRAPHY}

1. Brunner, G.W.: HEC-RAS, River Analysis System Hydraulic Reference Manual. Computer Documentation Report, Report No. CPD-69, US Army Corps of Engineers, Hydrologic Engineering Center (HEC) 2010

2. Majewski W.: Urban flash flood in Gdansk - 2001 Case study. Meteorology Hydrology and Water Management Research and Operational Applications, 4(2), 2016, pp. 41-49.

3. Mikos-Studnicka P., Szydłowski M.: The Influence of Hydrological Data Quality on Estimating The Runoff From City Catchment On The Example Of Strzyża Stream In Gdańsk, Ecological Engineering, 44, 2015 , pp. 139-153.

4. Mrokowska M. M., Rowiński P. M., Książek L., Strużyński A., Wyrębek M., Radecki-Pawlik A.: Laboratory studies on bedload transport under unsteady flow conditions, Journal of Hydrology and Hydromechanics, 66(1), 2018, pp. 23-31. doi: https://doi.org/10.1515/johh-2017-0032

5. Szpakowski W., Szydłowski M. : Probable Rainfall in Gdańsk in View of Climate Change. Acta. Sci. Pol., Form. Cir., 17(3), 2018, pp. 175-183.

6. Szydłowski M., Szpakowski W., Zima P.: Numerical simulation of catastrophic flood: the case study of hypothetical failure of the Bielkowo hydro-power plant reservoir, Acta Geophysica, 61(5), 2013, pp. 1229

7. Weinerowska-Bords K., Szydłowski M, Bielecka K. : Analysis of temporal and spatial variability of precipitation in the Strzyza catchment in Gdańsk, Inżynieria Morska i Geotechnika, 6. , 2012

8. Weinerowska-Bords K. : Development of Local IDF-formula Using Controlled Random Search Method for Global Optimization. Acta Geophysica, 63(1), 2014, pp. 232-274.
9. Widerski T., Szydłowski M., Szpakowski W. : Measurement and analysis of a flood wave propagation on the Kacza River in Gdynia in Northern Poland. $17^{\text {th }}$ International Multidisciplinary Scientific GeoConference SGEM2017, Water Resources. Forest, Marine and Ocean Ecosystems, 2017, pp. 453-460.

10. Zima P. : Modeling of the Two-Dimensional Flow Caused by Sea Conditions and Wind Stresses on the Example of Dead Vistula. Polish Maritime Research, Vol. 25, iss. s1(97), 2018, pp. 166-171.

\section{CONTACT WITH THE AUTHOR}

\author{
Michał Szydłowski \\ e-mail:mszyd@pg.edu.pl
}

Gdańsk University of Technology

Faculty of Civil and Environmental Engineering

11/12 Narutowicza St. 80 - 233 Gdańsk

Poland 